\title{
Avaliação experimental dos fatores de influência na aderência de revestimentos de gesso em pasta
}

\author{
Evaluation of the types of base in the adhesion of gypsum \\ plasters coating
}

\section{Angelo Just da Costa e Silva João Manuel do Paço Quesado Delgado Antônio Augusto Costa de Azevedo}

\section{Resumo}

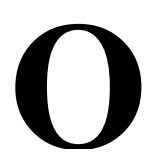

uso de pastas de gesso como revestimento de paredes internas é uma das técnicas mais comumente empregadas em obras no Brasil, geralmente efetuado em pequenas espessuras por meio de aplicação manual ou, ainda em menor espessura, por projeção mecânica. $\mathrm{O}$ presente trabalho objetivou avaliar experimentalmente a resistência de aderência de revestimentos executados em pasta de gesso com aplicação manual em diferentes substratos e alturas de aplicação. Como variáveis foram testados quatro tipos de blocos (blocos cerâmicos e de concreto, com função de vedação e estruturais), duas profundidades de ensaio da pasta (superficial e com cortes até o substrato) e três alturas de aplicação (até $0,6 \mathrm{~m}$; entre $0,6 \mathrm{~m}$ e 1,2 $\mathrm{m}$; e acima de $1,2 \mathrm{~m}$ ). Os resultados apontaram a forte influência da base e da profundidade de corte na aderência, o que não foi encontrado na altura de aplicação do revestimento (ergonomia), em decorrência do natural processo de aplicação da pasta de gesso efetuado com pressão da massa sobre a parede.

Palavras-chave: Pasta de gesso. Ergonomia. Resistência de aderência. Substrato.

${ }^{1}$ Angelo Just da Costa e Silva ${ }^{1}$ Universidade Católica de Pernambuco Recife - PE - Brasil

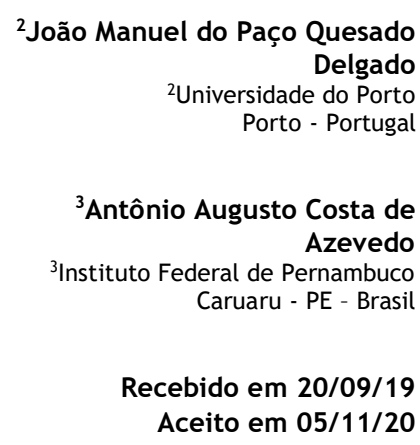

Recebido em 20/09/19 Aceito em 05/11/20

\section{Abstract}

The use of gypsum plaster paste as an internal wall covering is one of the most commonly used techniques in Brazil, usually made in small thicknesses by manual application or by mechanical projection. This study evaluates, experimentally, the adhesion strength of coatings made with gypsum plaster paste, considering different substrates and application heights. Four types of blocks (ceramic and concrete blocks, sealing and structural blocks), two types of slice cuttings (superficial and even substrate) and three application heights (up to $0.6 \mathrm{~m}$, between $0.6 \mathrm{~m}$ and $1.2 \mathrm{~m}$, and above $1.2 \mathrm{~m}$ ) were used. The results indicated a strong influence of the base and depth of cut on the adhesion, but no influence of the application height on adherence was identified, due to the natural process of the application of the gypsum plaster coating.

Keywords: Gypsum plaster. Ergonomics. Adhesion strength. 


\section{Introdução}

O uso dos revestimentos em pasta de gesso para ambientes internos é uma prática corrente em várias partes do mundo, inclusive no Brasil, que dispõe de reservas minerais de gipsita de grande pureza e quantidade, especialmente na região do Araripe, localizada no extremo leste do estado de Pernambuco (BALTAR; BASTOS; LUZ, 2005; BARBOSA; FERRAZ; SANTOS, 2014; LYRA, 2002; PERES; BENACHOUR; SANTOS, 2008).

Normalmente empregados em baixas espessuras (na ordem de $5 \mathrm{~mm}$ a $20 \mathrm{~mm}$ ), em geral possuem uma técnica de aplicação que utiliza desempenadeiras ou réguas lisas, que são pressionadas pelo operário ao encontro da base, ao contrário do lançamento enérgico que ocorre no caso dos revestimentos de argamassa à base de cimento. Isso obriga a utilização de uma massa com consistência pastosa, para que não fique escorrendo após a aplicação (COSTA E SILVA et al., 2017).

A depender das necessidades da obra e da construtora, esse revestimento pode ser aplicado sobre diferentes bases (estruturas de concreto, blocos cerâmicos, blocos de concreto, entre outros).

Nesses termos, o presente trabalho avalia, por meio de um estudo experimental, a aderência à tração de pastas de gesso executadas sobre diferentes bases, analisando ainda a influência da altura de aplicação e a profundidade de corte.

\section{Dados de literatura}

\section{Uso do gesso como revestimento}

O uso do gesso na construção civil é muito comum em diversas partes do mundo, especialmente para a confecção de forros, elementos de vedação vertical interna (chapas acartonadas, blocos maciços ou alveolares), e como pastas de gesso com função de revestimento (PAULA et al., 2017a, 2017b; SANTOS et $a l ., 2019)$. O gesso de construção, obtido a partir do mineral gipsita, é essencialmente constituído por um silicato de cálcio hemi-hidratado, podendo ainda conter pequenas quantidade do silicato bi-hidratado, além de eventuais impurezas (FLORES-COLEN; BRITO; BRANCO, 2009; ROBADOR; ARROYO, 2013).

Em função da baixa temperatura requerida para a calcinada do mineral gipsita (entre $150{ }^{\circ} \mathrm{C}$ e $300{ }^{\circ} \mathrm{C}$ ), apresenta-se como uma alternativa interessante também sob o ponto de vista ambiental, quando comparado com outros ligantes inorgânicos, como o cimento Portland e a cal. Por outro lado, apresenta como restrição a perda de sua capacidade mecânica quando em contato permanente com a água, o que dificulta seu uso em áreas molhadas (aglomerante aéreo).

Segundo Peres, Benachour e Santos (2008), cerca de 94\% da produção de gesso de construção no Brasil é oriunda da região do Araripe, localizada no extremo oeste do estado de Pernambuco, onde a pureza do mineral encontrado (96\%) favorece a obtenção de produtos de qualidade superior.

Em decorrência do uso cada vez mais intenso do gesso em obras espalhadas por todo o país, nos últimos anos têm sido desenvolvidos estudos diversos que culminaram com a publicação de diferentes normativas nacionais que tratam tanto do gesso como material, como dos diferentes componentes e sistemas (revestimento e alvenaria) utilizados com esse produto.

\section{Aplicação do gesso em pasta como componente do sistema de revestimento}

As pastas de gesso usadas em revestimentos de áreas internas são geralmente empregadas em pequenas espessuras, sobre substratos executados com blocos de concreto, tijolos cerâmicos, ou mesmo sobre estruturas de concreto (pilares, vigas, etc.). Diferentemente do que acontece no caso das argamassas cimentícias utilizadas em elementos verticais (paredes), a aplicação das pastas de gesso é efetuada por pressão da massa sobre a base, geralmente com desempenadeiras plásticas ou metálicas de diferentes tamanhos (Figura 1).

Por conta dessa particularidade, os produtores necessitam fazer alguns ajustes no processo fabril, tanto na viscosidade quanto no tempo de pega. É preciso que a massa apresente uma consistência mais pastosa durante todo o tempo de aplicação do revestimento, então são colocados aditivos no gesso para postergar o tempo de início da pega e permitir a manutenção da viscosidade ao longo do uso pelos operários (Figura 2).

350 Costa e Silva, A. J. da; Delgado, J. M. P. Q.; Azevedo, A. A. C. de 
Figura 1 - Imagens da aplicação de revestimento de gesso manual (áreas internas)
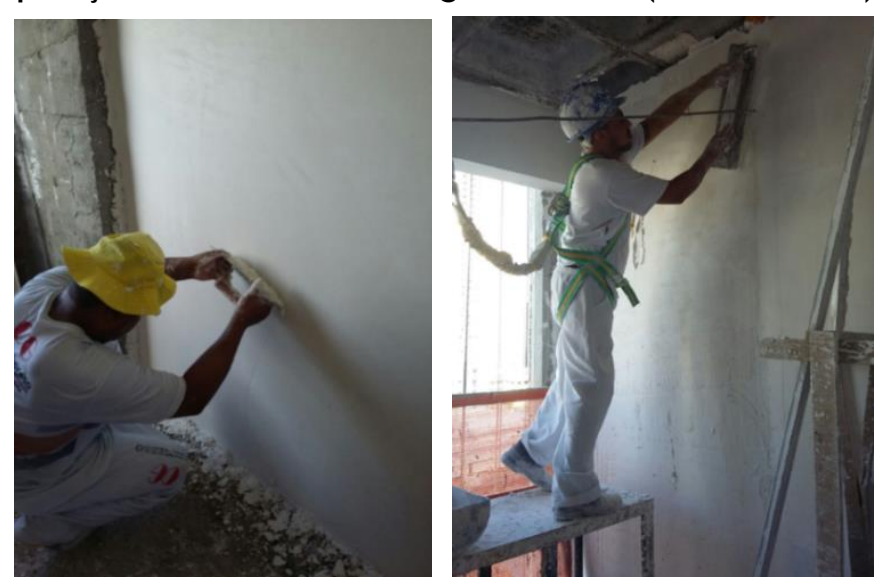

Figura 2 - Comportamento ajustado das pastas de gesso de revestimento para correção da viscosidade e do tempo de pega

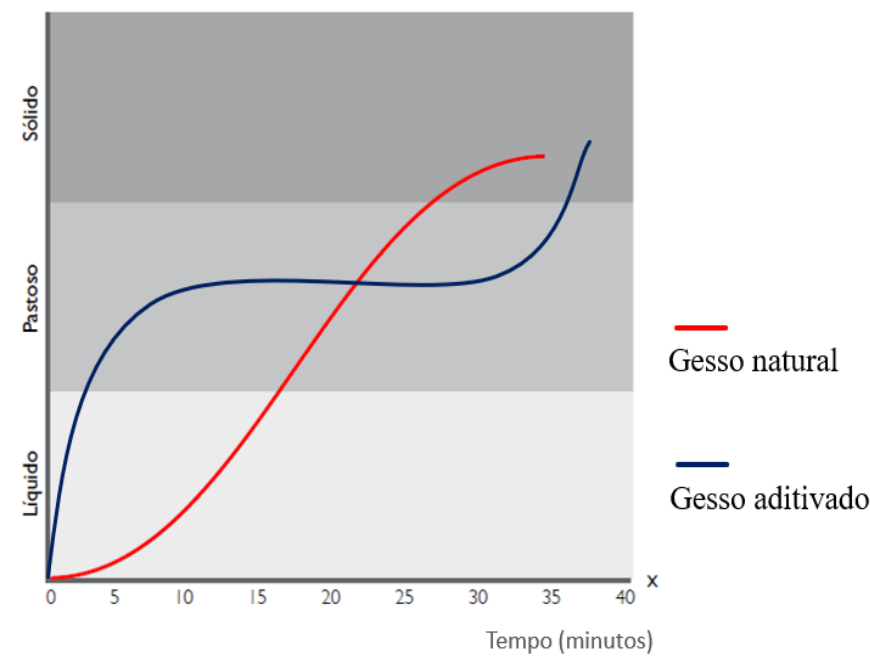

Fonte: adaptado de Peres et al. (2008).

Em decorrência disso, é natural imaginar que a influência da ergonomia (especialmente a altura de aplicação) seja menor para a aplicação por pressão em comparação com os processos tradicionais, que ocorrem por meio de lançamento enérgico. Trabalho apresentado por Costa e Silva et al. (2017) ilustra essa situação, o que sugere maior homogeneidade da aderência.

Além do processo tradicional, também se observa o uso crescente de aplicação de pastas de gesso por projeção mecânica, o que igualmente exige o ajuste nas propriedades básicas do material para permitir adequada fluidez da massa desde a máquina de projeção, passando pelo mangote até, finalmente, ser lançada na parede.

\section{Aderência de pastas de gesso sobre bases porosas}

A aderência entre pastas de gesso e bases de diferentes origens decorre de um fenômeno essencialmente físico, ou mecânico, diante do fluxo entre a pasta e os poros existentes no substrato. Por conta disso, torna-se evidente a influência das propriedades reológicas da pasta e da avidez por água da base, qualquer que seja a técnica de aplicação na parede (projeção manual ou mecânica).

No caso dos revestimentos cimentícios, são diversos os estudos relacionados com a percolação da pasta nos poros da base. Ye (2005) discute a evidente influência das características da base (porosidade, permeabilidade e ligação entre os poros ativos), além das características reológicas da pasta na fixação entre as camadas. 


\section{Materiais e métodos}

\section{Planejamento experimental}

O experimento foi realizado mediante ensaios de resistência de aderência à tração direta efetuados em pastas de gesso aplicadas sobre bases de blocos cerâmicos e de concreto, estruturais e de vedação (FREITAS et al., 2014; MELO et al., 2020). Para uma melhor visualização, são apresentadas na Figura 3 as variáveis dependentes e independentes utilizadas.

Em cada uma dessas bases foram realizados ensaios em 120 amostras, totalizando 480 testes de aderência, todos efetuados numa mesma data, após 28 de aplicação. A opção pela concentração dos testes apenas em uma idade se deu à predileção por uma maior quantidade de amostras por variável de estudo. Os quatro painéis foram levantados por um mesmo pedreiro, de modo que fossem divididas em quatro bases de dimensões 1,50 m (largura) x 1,80 m (altura), constituídos pelas diferentes bases citadas, ficando numa área coberta do Laboratório de Materiais da Universidade Católica de Pernambuco durante todo o período do experimento (Figura 4). Para a elevação das paredes foi empregada argamassa de assentamento de cimento industrializada, indicada pelo fornecedor para múltiplos usos, dosada conforme as indicações apresentadas na sacaria.

Figura 3 - Esquema ilustrativo do planejamento experimental

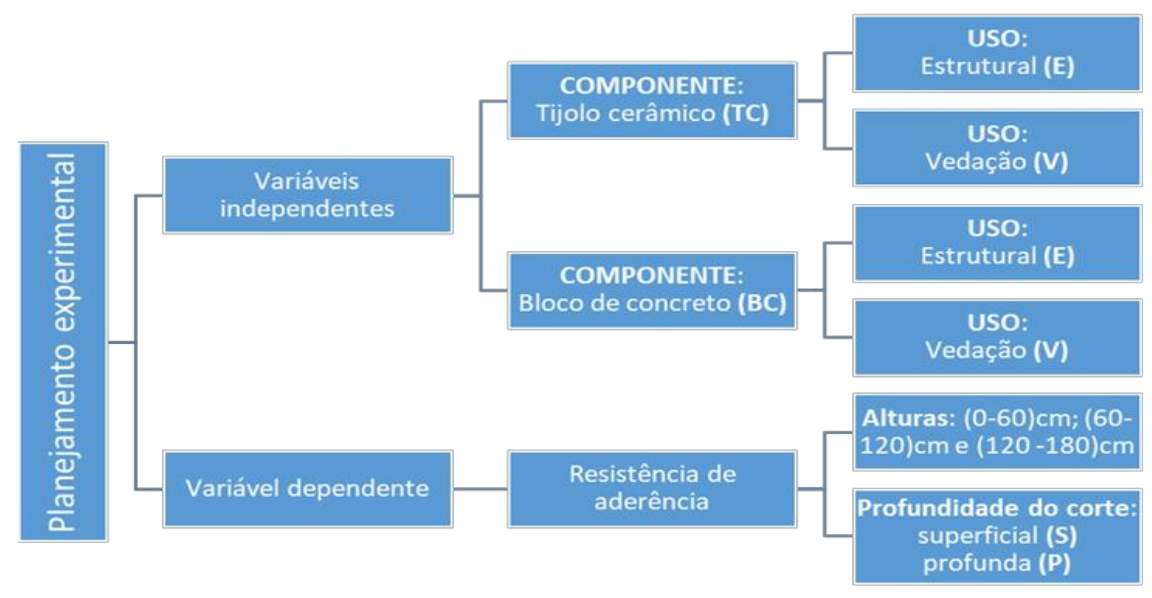

Figura 4 - Esquema de preparação das amostras para ensaio de aderência

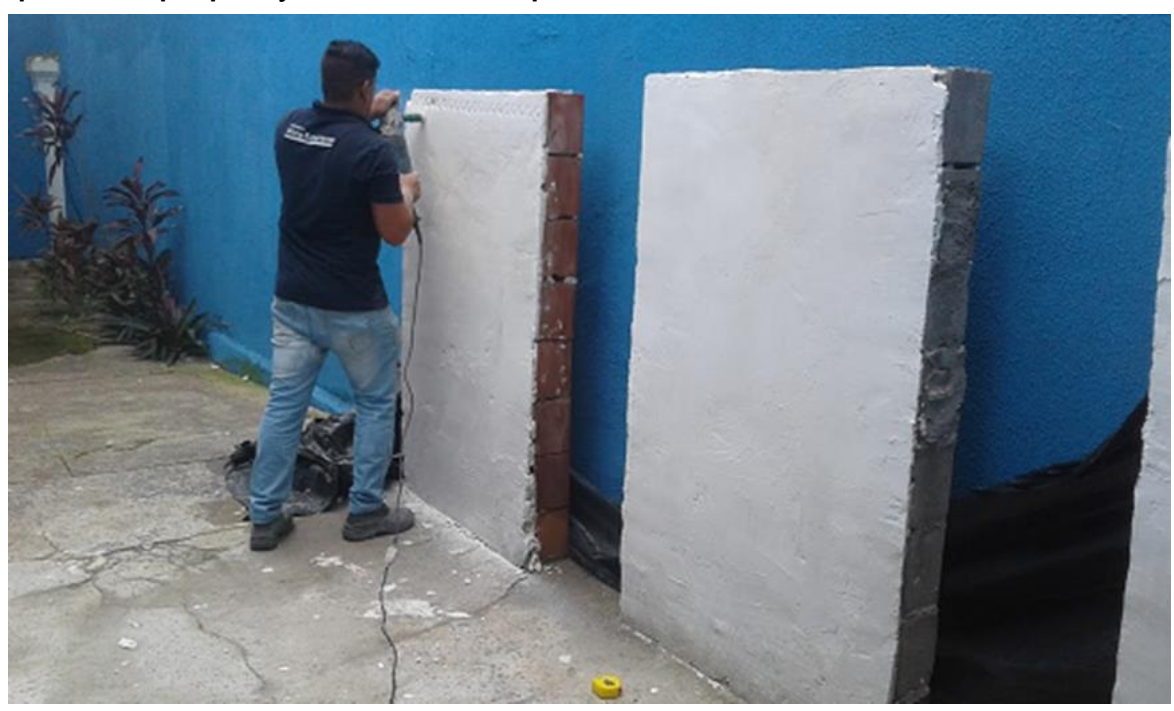

352 Costa e Silva, A. J. da; Delgado, J. M. P. Q.; Azevedo, A. A. C. de 
Após 7 dias do assentamento dos blocos, foi inicialmente efetuado o taliscamento, a fim de garantir a uniformidade da espessura da argamassa, estabelecida em $20 \mathrm{~mm}$, seguido da aplicação da pasta de gesso. Para essa etapa utilizou-se a técnica convencional empregada nesse tipo de revestimento, que consiste na compressão manual da pasta sobre a base, com o auxílio de desempenadeira de PVC. A quantidade de água adotada foi aquela indicada pelo fornecedor do produto em sua sacaria, e a mistura foi efetuada de forma manual, com a própria colher de pedreiro.

Antes da aplicação do revestimento não foi efetuado qualquer tipo de preparação da base, exceto por meio de uma limpeza superficial com escovação. Todas as etapas de execução da pasta de gesso foram realizadas pelo mesmo operário gesseiro, a fim de reduzir a influência do operador nos resultados encontrados.

\section{Materiais utilizados}

\section{Gesso de revestimento}

Foi utilizado o gesso para revestimento manual, material disponível na região. A Tabela 1 apresenta informações dos ensaios da caracterização física do produto, envolvendo normas e métodos de ensaio.

\section{Blocos}

O gesso utilizado para revestimento manual é material disponível na região. A Tabela 1 apresenta informações dos ensaios da caracterização física e química do produto envolvendo normas e métodos de ensaio. Foram utilizados nos experimentos blocos cerâmicos e blocos de concreto, de vedação e estrutural, todos caracterizados quanto a absorção total de água, resistência à compressão e determinação das dimensões (Tabela 2).

\section{Descrição dos ensaios}

Para a realização do experimento foram preparados painéis de alvenaria com blocos cerâmicos e de concreto (vedação e estrutural), revestidos com pasta de gesso. Os ensaios de resistência de aderência à tração atenderam ao procedimento descrito na NBR 13528 (ABNT, 2010), com 120 amostras por substrato, totalizando 480 ensaios. De notar que existem outros métodos de ensaio não abordados neste trabalho, como referido por Naderi (2005).

Tabela 1 - Resultados dos ensaios de caracterização do gesso em pó

\begin{tabular}{|c|c|c|}
\hline \multicolumn{2}{|c|}{ Ensaios } & Resultados \\
\hline \multicolumn{2}{|c|}{ Consistência normal } & $29,00(\mathrm{a} / \mathrm{g}: 0,54)$ \\
\hline \multirow{5}{*}{ Granulometria } & Peneira $0,840 \mathrm{~mm}$ & 0 \\
\hline & Peneira $0,420 \mathrm{~mm}$ & 0,3 \\
\hline & Peneira $0,210 \mathrm{~mm}$ & 6,98 \\
\hline & Peneira $0,840 \mathrm{~mm}$ & 17,45 \\
\hline & Peneira $0,105 \mathrm{~mm}$ & 75,27 \\
\hline \multicolumn{2}{|c|}{ Massa unitária (g) } & 719,85 \\
\hline \multicolumn{2}{|c|}{ Módulo de finura } & 0,32 (gesso fino) \\
\hline \multicolumn{2}{|c|}{ Resistência à compressão (MPa) } & 12,25 \\
\hline \multirow{2}{*}{ Tempo de pega } & Inicial & $00: 26: 38$ \\
\hline & Final & $00: 48: 10$ \\
\hline
\end{tabular}

Tabela 2 - Resultados dos ensaios de caracterização dos blocos

\begin{tabular}{l|c|c|c|c|c}
\hline \multirow{2}{*}{ Características analisadas } & \multirow{2}{*}{$\begin{array}{c}\text { Método de } \\
\text { ensaio }\end{array}$} & \multicolumn{2}{c|}{ Tijolo cerâmico } & \multicolumn{2}{c}{ Bloco de concreto } \\
\cline { 3 - 6 } & Vedação & Estrutural & Vedação & Estrutural \\
\hline Absorção total de água (\%) & $\begin{array}{c}\text { NBR 12118 } \\
\text { (ABNT, 2013) }\end{array}$ & 18 & 12,5 & 8 & 6,5 \\
Resistência à compressão (MPa) & $\begin{array}{c}\text { NBR 15270 } \\
(\text { ABNT, 2017a) }\end{array}$ & 1,2 & 2,7 & 3,4 & 6,6 \\
Dimensões - LxCxA (cm) & --- & $(9 x 19 x 19)$ & $(14 \times 39 x 19)$ & $(19 \times 19 \times 19)$ & $(9 \times 39 \times 19)$ \\
\hline
\end{tabular}


Para a colagem das peças metálicas necessárias ao ensaio de aderência, os painéis foram divididos em três alturas diferentes, para permitir a avaliação da influência da ergonomia, com cortes efetuados procurando-se evitar coincidir com as juntas de assentamento horizontais dos painéis, objetivando evitar a influência desses elementos na aderência. A profundidade de $20 \mathrm{~mm}$ do corte era controlada com uma marcação efetuada na própria serra-copo, enquanto na avaliação superficial as placas metálicas eram coladas diretamente sobre a pasta, sem delimitação por corte, conforme preconiza a NBR 13755 (ABNT, 2017b) para esse tipo de avaliação.

\section{Resultados e discussões Influência do tipo de base}

As Figuras 5 e 6 apresentam os valores obtidos nas 480 amostras ensaiadas, separadas apenas de acordo com o tipo de componente utilizado na base.

A diferença de resultado entre essas bases pode ser creditada à maior rugosidade encontrada nos blocos de concreto, o que ajuda na macroancoragem do gesso à base e diminui as deficiências na área de contato. Ressalta-se que, nos casos dos blocos de concreto, não se observou diferença expressiva pelo fato de ser estrutural ou de vedação, ao contrário dos tijolos cerâmicos, provavelmente pela natural rugosidade elevada dos blocos de concreto (SCARTEZINI, 2002).

Figura 5 - Resultado geral das 480 amostras ensaiadas, separadas por tipo de base

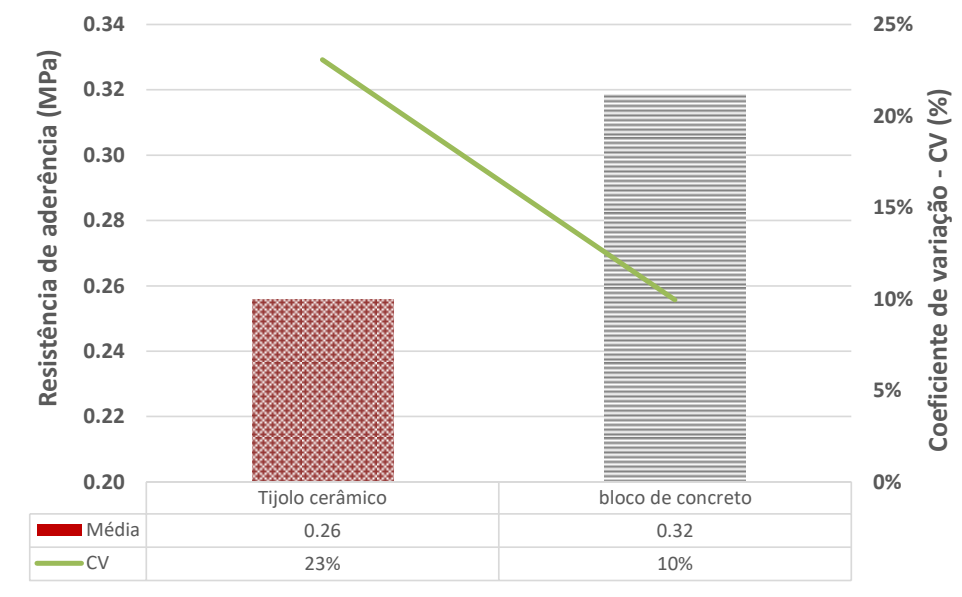

Figura 6 - Resultados comparativos dos blocos estruturais e de vedação

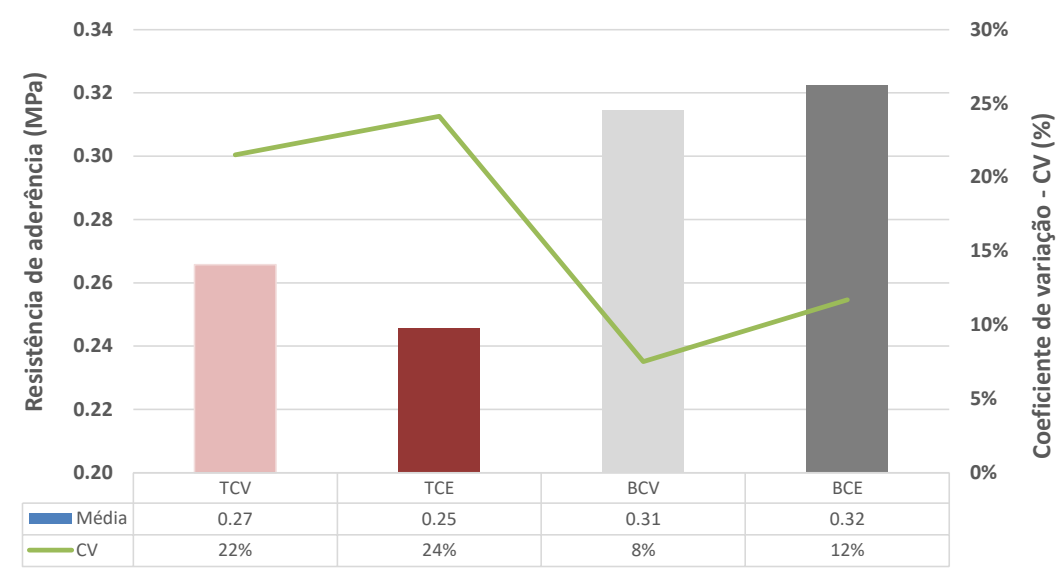

Nota: Legenda:

TCV: tijolo cerâmico de vedação;

TCE: tijolo cerâmico estrutural;

BCV: bloco cerâmico de vedação; e

BCE: bloco cerâmico estrutural.

354 Costa e Silva, A. J. da; Delgado, J. M. P. Q.; Azevedo, A. A. C. de 
De uma forma geral, destaca-se o tipo de ruptura predominantemente adesivo nas amostras (entre aquelas ensaiadas com corte da pasta), especialmente na ligação entre a pasta e a base, o que reforça sua influência na aderência do sistema.

Quanto aos coeficientes de variação, foram verificados valores maiores para o caso dos tijolos cerâmicos, provavelmente devido à natural maior heterogeneidade do processo fabril desse tipo de componente.

\section{Influência da profundidade do corte}

Na Figura 7 são apresentados os valores encontrados nas amostras ensaiadas, separadas conforme o tipo de base e a profundidade do ensaio. Os resultados apontaram leve perda de resistência de aderência nas amostras ensaiadas sem a realização dos cortes, ou seja, avaliando apenas sua capa superficial, independentemente da base. Esse comportamento pode ser creditado à exposição dessa camada superficial após sua execução, especialmente à presença de umidade natural, que tende a reduzir a resistência mecânica do gesso.

\section{Influência da altura de aplicação}

Na Figura 8 são apresentados os valores observados nas amostras ensaiadas, separadas conforme a altura de aplicação da pasta de gesso.

De uma maneira geral, observa-se que não houve diferenças expressivas entre as amostras ensaiadas nos planos inferior, central e superior com a pasta de gesso, independentemente da base sobre a qual foi aplicada. Esse fato decorre da técnica de aplicação desse revestimento, que não é efetuada de forma lançada, como ocorre com as argamassas de cimento (SCARTEZINI, 2002), o que obriga o aplicador a empurrar a massa de encontro à parede e, com isso, reduz as dispersões e a influência da ergonomia.

\section{Conclusões}

Os ensaios apresentados no presente estudo, parte integrante da dissertação de mestrado do autor, destacam a influência do tipo de base (blocos cerâmicos e de concreto, de vedação e estruturais) e da profundidade do corte (profunda ou superficial) no comportamento da aderência mecânica das pastas de gesso utilizadas como revestimento interno vertical.

Figura 7 - Resultados dos ensaios superficial (S) e com a delimitação do corte na pasta de gesso (P profundo)

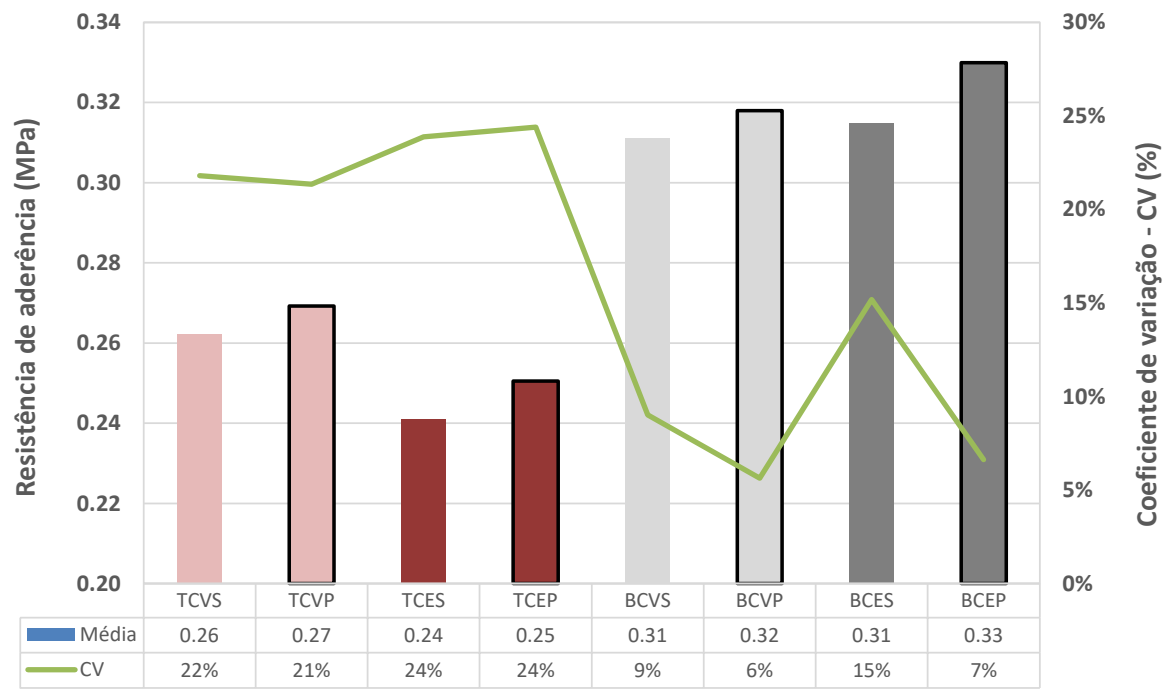

Nota: Legenda:

TCV: tijolo cerâmico de vedação;

TCE: tijolo cerâmico estrutural;

BCV: bloco cerâmico de vedação; e

BCE: bloco cerâmico estrutural. 
Figura 8 - Resultados gerais de aderência em diferentes alturas

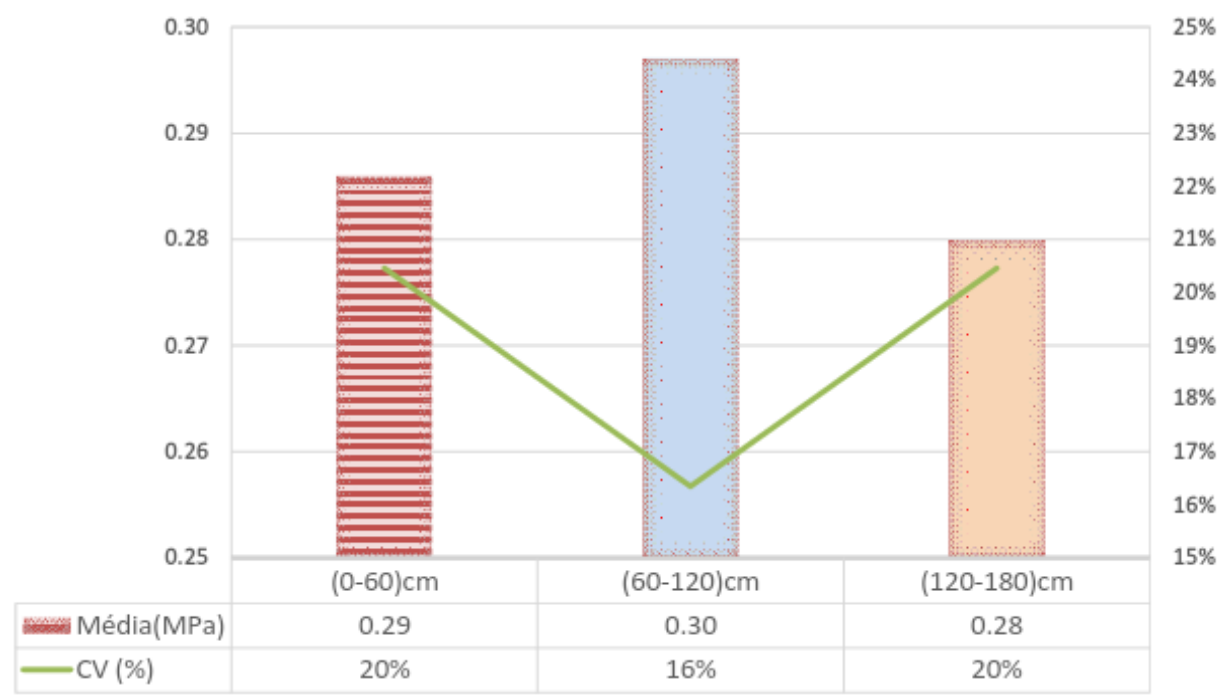

Ressalta-se que, como já observado em outras pesquisas, a ergonomia do aplicador, avaliada a partir dos ensaios separados em diferentes alturas, não se mostrou relevante nos dados estudados, o que deve ser oriundo da técnica de execução, que se utiliza de um esforço de pressão contínuo da pasta sobre a parede, ao contrário do lançamento enérgico, normalmente empregado nas argamassas mistas de cimento.

Em todos os casos foram encontrados valores de resistência de aderência superiores a 0,20 $\mathrm{MPa}$, que atendem às exigências apresentadas pela NBR 13281 (ABNT, 2005) para usos em ambientes internos, situação na qual são empregadas as pastas de gesso para revestimentos estudadas nesta pesquisa.

Ressalta-se que os resultados apresentados devem ser restritos aos materiais empregados na presente pesquisa, não se podendo generalizá-los para todos os tipos de blocos e de gesso utilizados em obras. Contudo, a expressiva quantidade de amostras utilizadas (480) representa uma tendência de comportamento importante desse tipo de solução de revestimento empregado em ambientes internos de edificações.

\section{Referências}

ASSOCIAÇÃO BRASILEIRA DE NORMAS TÉCNICAS. NBR 12118: blocos vazados de concreto simples para alvenaria: métodos de ensaio. Rio de Janeiro, 2013.

ASSOCIAÇÃO BRASILEIRA DE NORMAS TÉCNICAS. NBR 13281: argamassa para assentamento e revestimento de paredes e tetos: requisitos. Rio de Janeiro, 2005.

ASSOCIAÇÃO BRASILEIRA DE NORMAS TÉCNICAS. NBR 13528: revestimentos de paredes e tetos de argamassa inorgânicas: determinação de resistência de aderência à tração. Rio de Janeiro, 2010.

ASSOCIAÇÃO BRASILEIRA DE NORMAS TÉCNICAS. NBR 13755: revestimentos cerâmicos de fachadas e paredes externas com utilização de argamassa colante: projeto, execução, inspeção e aceitação: procedimento. Rio de Janeiro, $2017 \mathrm{~b}$.

ASSOCIAÇÃO BRASILEIRA DE NORMAS TÉCNICAS. NBR 15270: componentes cerâmicos: blocos e tijolos para alvenaria: parte 2: Mmétodos de ensaios. Rio de Janeiro, 2017a.

BALTAR, C. A. M.; BASTOS, F. de F.; LUZ, A. B. Gipsita. Rio de Janeiro: Cetem, 2005.

BARBOSA, A. A.; FERRAZ, A. V.; SANTOS, G. A. Caracterização química, mecânica e morfológica do gesso $\beta$ obtido do polo do Araripe. Petrolina: Univasf, 2014.

COSTA E SILVA, A. J. et al. Estudo comparativo da aderência de revestimentos de gesso aplicados por projeção mecânica e manual. In: SIMPÓSIO BRASILEIRO DE TECNOLOGIA DAS ARGAMASSAS, 12. São Paulo, 2017. Anais [...] São Paulo, 2017.

FLORES-COLEN, I.; BRITO, J.; BRANCO, F. In situ adherence evaluation of coating materials.

Experimental Techniques, v. 33, n. 3, p. 51-60, 2009. 
FREITAS, V. et al. Assessing the durability of mortar tiles: a contribution for a prediction model. Engineering Failure Analysis, v. 44, p. 36-45, 2014.

LYRA, A. C. O mercado de gipsita e gesso no Brasil. Vortal Cadeia Produtiva do Gesso, 2002. Disponível em: http://www5.prossiga.br/gesso/index.html. Acesso em: 5 ago. 2020.

MELO, A. et al. Influence of the contact area in the adherence of mortar: ceramic tiles interface.

Construction and Building Materials, v. 243, 118274, 2020.

NADERI, M. Friction-transfer test for the assessment of in situ strength and adhesion of cementitious materials. Construction and Building Materials, v. 19, p. 454-459, 2005.

PAULA, P. et al. Hygrothermal performance of Gypsum plaster houses. Diffusion Foundations, v. 14, p. 128-157, 2017a.

PAULA, P. et al. Numerical analysis of hygrothermal building performance of gypsum houses in different Brazilian climates. Diffusion Foundations, v. 10, p. 132-148, 2017 b.

PERES, L.; BENACHOUR, M.; SANTOS, V. A. Gesso: produção e utilização na construção civil. Recife: Sebrae, 2008

ROBADOR, M. D.; ARROYO, F. Characterization of Roman coatings from a Roman house in Mérida (Spain). Journal of Cultural Heritage, v. 14, n. 3, p. S52-S58, 2013.

SANTOS, A. et al. Hygrothermal performance of Brazilian gypsum walls. Journal of Building Physics, v. 42, n. 4, p. 605-626, 2019.

SCARTEZINI, L. M. Influência do tipo e preparo do substrato na aderência dos revestimentos de argamassa: estudo da evolução ao longo do tempo influência da cura e avaliação da perda de água da argamassa fresca. Goiânia, 2002. Dissertação (Mestrado em Engenharia Civil) - Universidade Federal de Goiás, Goiânia, 2002.

YE, G. Percolation of capillary pores in hardening cement pastes. Cement and Concrete Research, v. 35, p. 167-176, 2005.

Angelo Just da Costa e Silva

Departamento Engenharia Civil | Universidade Católica de Pernambuco | Rua do Príncipe, 526, Boa Vista | Recife - PE - Brasil | CEP 50050-900 | Tel.: (81) 2119-4000 | E-mail: angelo@tecomat.com.br

João Manuel do Paço Quesado Delgado

Departamento Engenharia Civil, Faculdade de Engenharia | Universidade do Porto | Rua Dr. Roberto Frias, s/n | Porto - Portugal | Tel.: + (351) 22508-1404 | E-mail: jdelgado@fe.up.pt

Antônio Augusto Costa de Azevedo

Departamento de Construção | Instituto Federal de Pernambuco | Estrada do Alto do Moura, KM 3,8, s/n, Distrito Industrial III | Caruaru PE - Brasil | CEP 55040-120 | Tel.: (81) 3046-1300 | E-mail: antonio.costaazevedo@fe.up.pt

\section{Ambiente Construído}

Revista da Associação Nacional de Tecnologia do Ambiente Construído

Av. Osvaldo Aranha, $99-3^{\circ}$ andar, Centro

Porto Alegre - RS - Brasil

CEP 90035-190

Telefone: +55 (51) 3308-4084

Fax: +55 (51) 3308-4054

www.seer.ufrgs.br/ambienteconstruido

E-mail: ambienteconstruido@ufrgs.br 